\title{
Avaliação dos Métodos Não Farmacológicos para Alívio da Dor (MNFAD) no trabalho de parto por puérperas
}

\author{
Evaluation of Non-Pharmacological pain Relief Methods (MNFAD) in pupper working \\ Evaluación de Métodos de Alivio del Dolor no Farmacológico (MNFAD) en el trabajo de \\ muchacho
}

Amanda Gabriele Nascimento Sousa ${ }^{1 *}$, Jessica Ellen Goncalves da Silva ${ }^{1}$, Mara Ramel de Sousa Silva ${ }^{1}$, Raiana Soares de Sousa Silva ${ }^{2}$, Arlene da Silva Fontinele ${ }^{3}$, Francilio Williams de Sousa Silva ${ }^{3}$, Gabrielle Ribeiro de Sá ${ }^{4}$, Bruno Emanuel de Santana Ribeiro ${ }^{1}$, Suianne Nadja Lima de Carvalho ${ }^{5}$, Leidinar Cardoso Nascimento ${ }^{2}$.

\section{RESUMO}

Objetivo: Analisar na literatura a percepção das puérperas sobre os Métodos Não Farmacológicos para o Alívio da Dor MNFAD no trabalho de parto. Métodos: Trata-se de uma revisão integrativa da literatura realizada nas bases de dados LILACS, BDENF, MEDLINE e na biblioteca eletrônica SciELO via periódicos Capes, no período de outubro e novembro de 2018. Resultados: Observou-se que os estudos são em sua totalidade publicados em periódicos nacionais, evidenciando uma preocupação nacional com a questão da humanização do parto. Discussão: A utilização dos MNFAD apresenta diversos benefícios, ajuda acelerar o trabalho de parto, facilita o processo de dilatação e alivia a dor e mesmo com esses benefícios algumas delas não colaboram ou não se sentem à vontade para realizar. Considerações Finais: Para algumas puérperas nem todos os métodos não farmacológicos de alívio da dor são eficazes, mas no relato da maioria das puérperas pode sim proporcionar menos dor, diminuindo os níveis de ansiedade e estresse.

Palavras-chaves: Dor do parto, Trabalho de parto, Parto humanizado, Enfermagem obstétrica.

\begin{abstract}
Objective: To analyze in the literature the view of puerperae on the MNFAD during labor. Methods: This is an integrative review of the literature in LILACS databases, BDENF, MEDLINE and in the SciELO electronic library via periodical Capes, in the period of October and November of 2018. Results: It was observed that the studies are published in their entirety in national journals, evidencing a national concern with the issue of the humanization of childbirth. Discussion: The use of MNFAD presents several benefits, helps to accelerate labor, facilitates the process of dilation, and alleviates pain and even with these benefits some of them do not collaborate or feel uncomfortable to perform. Final considerations: Are observed for some puerperal patients, not all non-pharmacological methods of pain relief are effective, but in the report of most puerperas it can provide less pain, decreasing anxiety and stress.
\end{abstract}

Key words: Labor pain, Labor, Humanized birth, Obstetric nursing.

${ }^{1}$ Centro Universitário Maurício de Nassau (UNINASSAU), Teresina - PI.

*E-mail: amandagabriellyns@gmail.com

2Universidade Federal do Piauí (UFPI), Teresina - PI.

${ }^{3}$ Centro Universitário Uninovapi (UNINOVAFAPI), Teresina - PI.

${ }^{4}$ Centro Universitário UniFacid WYDEN (UNIFACID-WYDEN), Teresina - PI.

${ }^{5}$ Universidade Estadual do Piauí (UESPI), Teresina - PI.

SUBMETIDO EM: 11/2019 | ACEITO EM: 12/2019 | PUBLICADO EM: 6/2020 


\section{RESUMEN}

Objetivo: Analizar en la literatura la percepción de las mujeres posparto sobre Métodos No Farmacológicos para el Alivio del Dolor MNFAD en trabajo de parto. Métodos: Esta es una revisión de literatura integradora realizada en las bases de datos LILACS, BDENF, MEDLINE y Biblioteca electrónica SciELO a través de revistas Capes, de octubre a noviembre de 2018. Resultados: Se observo que todos los estúdios se publican em revistas nacionales, ló que muestra uma preocupación nacional com El tema de La humanizacion Del parto. Discusión: El uso de MNFAD tiene vários benefícios algunos de ellos no colaboran o se sienten incômodos de realizar. Consideraciones finales: Para algunas mujeres posparto, no todos lós métodos de alivio Del dolor no farmacológicos son efectivos, pero en El informe de La mayoria de lãs madres, puede proporcionar menos dolor, ló que reduce lós niveles de ansiedad y estrés.

Palabras clave: Dolor de parto, Trabajo de parto, Parto humanizado, Enfermería obstétrica.

\section{INTRODUÇÃO}

Até o século XVIII as mulheres tinham seus filhos em casa, o parto era um acontecimento domiciliar, familiar onde a assistência pertencia as parteiras, pessoas que possuíam conhecimento sobre o processo de nascimento. A partir do século XX esta prática foi transferida para o ambiente hospitalar, o parto passou a ser geralmente realizado pelo profissional médico como o principal autor desse processo, e que realiza procedimentos intervencionistas. Assim, o médico e a equipe multiprofissional deixam de lado a circunstância emocional que envolve esse momento, retirando da mulher a autonomia de seu corpo e todo o seu poder e desejo de atuar como protagonista desse processo (PEREIRA TCB, et al., 2016).

A organização Mundial de Saúde (OMS) recomenda o parto natural humanizado, pelo fato de haver comprovações na redução dos riscos maternos e neonatais. Sabendo disto existe distinção entre o parto normal e natural, pois no parto normal são utilizados intervenções ou, seja são utilizados de maneira comum muitos procedimentos, o que favorece e conduz ao aumento de cesáreas na maioria das vezes desnecessários, como a episiotomia, utilização de soro, bloqueio da ingesta de alimentos, tricotomia, o repouso na cama hospitalar, a proibição de um acompanhante, essa rotina utilizada durante o processo de parto causam ainda mais sofrimento, dor, aumentando os riscos de complicações para mãe e bebê (BRASIL, 2015).

O Ministério da Saúde instituiu, em todo território brasileiro, através da Portaria/GM n. 569 de 1 de junho de 2000, o Programa de Humanização no Pré-natal e Nascimento (PHPN), voltado para avaliar as necessidades de atenção à gestante, recém-nascido e à mãe no puerpério, melhorando o acesso, cobertura e qualidade no atendimento (BRASIL, 2002).

A humanização do parto normal traz benefícios para mãe e para o bebê. A mulher pode controlar melhor a dor nesse momento, ser mais comunicativa e do ponto de vista emocional ela pode ter uma experiência de mais participação no que é considerado um momento muito importante em sua vida, fecha-se um ciclo que é especialmente único em cada gestação. O Programa de Humanização no Pré-natal e Nascimento (PHPN) supõe uma série de técnicas a serem adotadas, que visa garantir um parto em que haja maior atuação ativa da parturiente, e que o nascimento seja cercado de menos traumas e interferências desnecessárias, o que, segundo o Programa haveria uma diminuição nas solicitações de cesárea (FRANKLIN JS e BITTAR CMA, 2015).

Em relação a este fator, prestar uma assistência humanizada no parto garante respeito ao direito da mulher e da criança, com procedimentos baseadas em evidências científicas, a utilização dos Métodos Não Farmacológicos para o Alívio da Dor (MNFAD) garante a puérpera mais autonomia sobre o trabalho de parto, buscando a diminuição da dor, tensão e estresse, tornando este processo mais natural possível (KATZER T, 2016). Essa prática, diminui a dor provocada pelas contrações uterinas, cresce o bem-estar materno e favorece os resultados obstétricos de forma que as gestantes mostram-se mais contribuintes, pois estima a sensação de domínio que possuem ao exercitar ativamente a dor e a ajuda que recebem de 
seu acompanhante e cuidadores, além da livre escolha de escolher seus movimentos, exercícios e para os profissionais da saúde, essas estratégias são favoráveis, pois contribuem para a redução do estresse, da ansiedade e do uso de medicamentos (FORMIGA AC, et al., 2016).

Entre os MNFAD pode-se referir: o uso de acompanhante, deambulação, banho de chuveiro, massagens, exercícios de respiração e exercícios de relaxamento muscular, bola suíça, cavalinho. Essas técnicas podem ser colocadas de forma que estejam conectadas ou separadas. O uso dos métodos vem sendo estudado desde a década de sessenta, todavia, foram colocadas em algumas maternidades do Brasil no início da década de noventa, com a humanização do parto e com as orientações do Ministério da Saúde (MS) para assistência do processo de nascimento (MEDEIROS J, et al., 2015).

Este desejo de análise da eficácia dos MNFAD no trabalho de parto pelo relato de puérperas é justificado, pois traz uma abordagem mais humanizada no acolhimento e no suporte das gestantes a conhecer esse momento de uma forma mais favorável, confortável e menos traumática. Sendo assim, esta pesquisa teve como objetivo analisar na literatura a percepção das puérperas sobre os Métodos Não Farmacológicos para o Alívio da Dor MNFAD no trabalho de parto.

\section{MÉTODOS}

O trabalho se trata de uma revisão bibliográfica com característica narrativa. A primeira etapa foi determinar a escolha da questão de pesquisa, a segunda etapa foi a determinação dos critérios de inclusão e exclusão de artigos e a procura na literatura foi dada pela busca das publicações nas bases de dados Base de Dados em Enfermagem (BDENF), Literatura Latino-Americana e do Caribe em Ciências da Saúde (LILACS), via Biblioteca Virtual em Saúde (BVS) e Medical Literature Analysis and Retrieval System Online (MEDLINE) e na biblioteca eletrônica Scientific Eletronic Library Online (SciELO), via periódicos Capes, no período de outubro e novembro de 2018, por meio das palavras chaves: Dor do parto; Trabalho de parto; Parto humanizado; Métodos não farmacológicos e Enfermagem Obstétrica, além disso foi empregue o operador AND (Dor do parto and Trabalho de parto and Parto humanizado e Métodos não farmacológicos and Enfermagem Obstétrica).

A estratégia de busca ocorreu da seguinte forma: pesquisa por palavras chaves, leitura de títulos e resumos preferindo-se aqueles que se tratou-se do tema discutido, os que possuem relatos de puérperas sobre o uso dos MNFAD no trabalho de parto e que atenderam aos objetivos do estudo.

Como critérios de inclusão optamos por utilizar artigos originais, liberados na íntegra e sem custos nas bases de dados e na biblioteca eletrônica selecionada, os anos dos periódicos foram entre 2007 a 2017 com idioma português. Foram eliminados os trabalhos que apresentaram repetição; os estudos de revisão, em formato de tese, dissertação e monografia; estudos de caso e os estudos cuja temática não contempla os objetivos definidos.

Vale ressaltar que foram analisados 12 artigos. No LILACS foram encontrados 22, porém, apenas 9 artigos atenderam aos critérios de inclusão, na base de dados BDENF foi encontrado 20 artigos, 5 mostraram critérios de inclusão mas 2 foi excluído por estar repetidos, nenhum trabalho foi encontrado na base de dados MEDLINE, na biblioteca SciELO foram encontrados 4 artigos, 1 atendia aos critérios de inclusão, mas foi excluído por ser artigo repetido.

$\mathrm{Na}$ terceira etapa foi tirado os dados dos artigos selecionados, incluindo: autor, título, ano de publicação, base de dados, desenho do estudo, MNFAD utilizados e a visão das puérperas. A quarta etapa foi realizado a avaliação dos artigos com análise das leituras sendo possível a obtenção de respostas ao problema que seria: Qual a eficácia dos métodos não farmacológicos de alívio da dor no trabalho de parto através de relatos das puérperas?

A quinta etapa correspondeu a colocar os resultados em quadros com uma análise detalhada das informações e abordados em categorias temáticas conforme os MNFAD utilizados e a visão das puérperas. Por fim, a sexta etapa convém a aparência da revisão, estabelecendo o agrupamento dos principais resultados evidenciados na análise dos estudos utilizados. 


\section{RESULTADOS E DISCUSSÃO}

De acordo com o planejamento da pesquisa, observou-se que os estudos são em sua totalidade publicados em periódicos nacionais, evidenciando uma preocupação nacional com a questão da humanização do parto. Os anos dos artigos selecionados foram entre 2007 a 2017 (Quadro 1).

Quadro 1 - Apresentação dos estudos a partir do ano de publicação, título e base de dados dos MNFAD incluídos na revisão integrativa, Teresina-PI, 2018.

\begin{tabular}{|c|c|c|c|}
\hline № & $\begin{array}{l}\text { Autor e Ano de } \\
\text { publicação }\end{array}$ & tons & Base de Dados \\
\hline 1 & $\begin{array}{l}\text { DAVIM RMB, et al. } \\
\text { (2007); }\end{array}$ & $\begin{array}{l}\text { Estratégias não farmacológicas no alívio da dor durante o } \\
\text { trabalho de parto: pré-teste de um instrumento. }\end{array}$ & LILACS \\
\hline 2 & $\begin{array}{l}\text { DAVIM RMB, et al. } \\
\text { (2008); }\end{array}$ & $\begin{array}{c}\text { Banho de chuveiro como estratégia não farmacológica no } \\
\text { alívio da dor de parturientes. }\end{array}$ & LILACS \\
\hline 3 & $\begin{array}{l}\text { SESCATO AC, et al. } \\
\text { (2008); }\end{array}$ & $\begin{array}{l}\text { Os cuidados não-farmacológicos para alívio da dor no } \\
\text { trabalho de parto: orientações da equipe de enfermagem. }\end{array}$ & LILACS \\
\hline 4 & $\begin{array}{l}\text { MIQUELUTTI MA, } \\
\text { et al. (2009); }\end{array}$ & A posição vertical durante o parto: dor e satisfação. & LILACS \\
\hline 5 & $\begin{array}{l}\text { YI WEI C, et al. } \\
\text { (2011); }\end{array}$ & $\begin{array}{l}\text { Movimentação e dieta durante o trabalho de parto: a } \\
\text { percepção de um grupo de puérperas. }\end{array}$ & LILACS \\
\hline 6 & $\begin{array}{l}\text { FRIGO J, et al. } \\
\text { (2013); }\end{array}$ & $\begin{array}{l}\text { Assistência de enfermagem e a perspectiva da mulher no } \\
\text { trabalho de parto e parto. }\end{array}$ & LILACS \\
\hline 7 & $\begin{array}{l}\text { ALMEIDA JM, et al. } \\
\text { (2015); }\end{array}$ & $\begin{array}{l}\text { Conhecimento das puérperas com relação aos métodos } \\
\text { não farmacológicos de alívio da dor do parto }\end{array}$ & BDENF \\
\hline 8 & $\begin{array}{l}\text { ARAÚJO ROCHA } \\
\text { FA, et al. (2015); }\end{array}$ & Cuidado no parto e nascimento: percepção de puérperas. & LILACS \\
\hline 9 & $\begin{array}{l}\text { BARBOSA DR e } \\
\text { TORRES GV } \\
\text { (2017); }\end{array}$ & $\begin{array}{c}\text { Avaliação do uso de estratégias não farmacológicas no } \\
\text { alívio da dor de parturientes. }\end{array}$ & BDENF \\
\hline 10 & $\begin{array}{l}\text { HANUM S dos P, et } \\
\quad \text { al. (2017); }\end{array}$ & $\begin{array}{l}\text { Estratégias não farmacológicas para o alívio da dor no } \\
\text { trabalho de parto: efetividade sob a ótica da parturiente. }\end{array}$ & BDENF \\
\hline 11 & $\begin{array}{l}\text { LIMA PC, et al. } \\
\quad(20170 ;\end{array}$ & $\begin{array}{l}\text { A vivência de adolescentes assistidas por enfermeiros } \\
\text { obstetras durante o processo de parturição. }\end{array}$ & LILACS \\
\hline 12 & $\begin{array}{l}\text { SOARES YKC, et } \\
\quad \text { al. (2017); }\end{array}$ & $\begin{array}{c}\text { Satisfação das puérperas atendidas em um centro de } \\
\text { parto normal. }\end{array}$ & LILACS \\
\hline
\end{tabular}

Fonte: Sousa AGN, et al., 2018.

Os resultados dos artigos encontrados foram classificados de acordo com o tema evidenciado em cada um dos resultados dos referidos artigos. Dessa maneira a discussão foi pautada em oito categorias, a saber. Dos MNFAD como o uso do Acompanhante, Bola Suíça, Cavalinho, Deambulação, Exercícios de respiração, Massagem e Relaxamento Muscular, Banho de chuveiro ou aspersão e Movimentação (posição vertical, agachamento e balanço pélvico). 


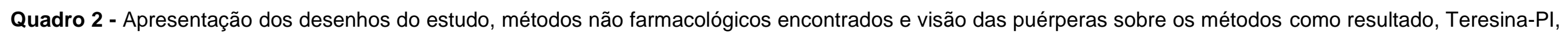
2018.

\begin{tabular}{|c|c|c|c|c|}
\hline № & Autor e Ano de publicação & Desenho do estudo & MNFAD & Resultados (Visão das puérperas) \\
\hline 1 & DAVIM RMB et al. (2007); & $\begin{array}{l}\text { Pesquisa quase-experimental do tipo } \\
\text { intervenção terapêutica não controlada e não } \\
\text { randomizada, com abordagem quantitativa. }\end{array}$ & $\begin{array}{l}\text { Deambulação; Técnicas de } \\
\text { Respiração; Massagem; } \\
\text { Acompanhante; Banho de } \\
\text { chuveiro; Balanço Pélvico. }\end{array}$ & $\begin{array}{l}\text { Percepções positivas: relataram melhoras } \\
\text { da dor com os métodos empregadas. }\end{array}$ \\
\hline 2 & DAVIM RMB, et al. (2008); & $\begin{array}{l}\text { Trata-se de um ensaio clínico quantitativo do } \\
\text { tipo intervenção terapêutica. }\end{array}$ & $\begin{array}{l}\text { Técnicas de Respiração; } \\
\text { Acompanhante; Deambulação; } \\
\text { Banho de chuveiro; Massagem. }\end{array}$ & $\begin{array}{l}\text { Percepç̃̃es negativas: no comportamento } \\
\text { doloroso comparando o "antes e após "à } \\
\text { aplicação do banho de chuveiro, não se } \\
\text { detectou diferença estatística significativa. } \\
\text { Percepções positivas: à aplicação do } \\
\text { banho de chuveiro nos } 8 \text { e } 9 \text { cm de } \\
\text { dilatação do colo uterino com o Teste T } \\
\text { pareado simples, verifica-se diferença } \\
\text { significativa, nos } 2 \text { momentos da fase ativa } \\
\text { do trabalho de parto, denotando a } \\
\text { efetividade dessa estratégia. }\end{array}$ \\
\hline 3 & SESCATO AC, et al. (2008); & Estudo qualitativo exploratório. & $\begin{array}{l}\text { Acompanhante; Deambulação; } \\
\text { Posição ereta; Cavalinho; Bola } \\
\text { suíça; Banho de aspersão; } \\
\text { Massagens; Posição de quatro. }\end{array}$ & $\begin{array}{l}\text { Percepcão positivas: puérpera relata que o } \\
\text { banho foi bem relaxante, e que o mesmo, a } \\
\text { massagem, e a deambulação aliviou } \\
\text { bastante a dor. }\end{array}$ \\
\hline 4 & $\begin{array}{l}\text { MIQUELUTTI MA, et al. } \\
\text { (2009); }\end{array}$ & $\begin{array}{l}\text { Análise secundária com uma avaliação } \\
\text { analítica da eficácia aplicada aos dados } \\
\text { resultantes de um estudo randomizado e } \\
\text { controlado. }\end{array}$ & $\begin{array}{l}\text { Acompanhante; Posição } \\
\text { vertical. }\end{array}$ & $\begin{array}{l}\text { Percepções positivas: as mulheres } \\
\text { relataram que posição vertical teve o alívio } \\
\text { na dor e aumentou o conforto. }\end{array}$ \\
\hline 05 & YI WEI C, et al. (2011); & $\begin{array}{l}\text { Estudo exploratório, descritivo, com análise } \\
\text { qualitativa. }\end{array}$ & $\begin{array}{l}\text { Banho; Deambulação; } \\
\text { Movimentação. }\end{array}$ & $\begin{array}{l}\text { Percepções negativas: apontada para as } \\
\text { seguintes questões: preferência em ficar } \\
\text { deitada, risco de o bebê nascer durante a } \\
\text { deambulação dificuldade para fazer força } \\
\text { na posição vertical. } \\
\text { Percepções positivas: banho aliviou } \\
\text { bastante a dor, e a metade das puérperas } \\
\text { referiu que a movimentação e } \\
\text { deambulação são benéficas. }\end{array}$ \\
\hline
\end{tabular}

REAS/EJCH | Vol.Sup.n.50 | e2583 | DOI: https://doi.org/10.25248/reas.e2583.2020 Página $\mathbf{5}$ de $\mathbf{1 0}$ 


\section{Revista Eletrônica Acervo Saúde / Electronic Journal Collection Health | ISSN 2178-2091}

\begin{tabular}{|c|c|c|c|c|}
\hline № & Autor e Ano de publicação & Desenho do estudo & MNFAD & Resultados (Visão das puérperas) \\
\hline 6 & FRIGO J, et al. (2013); & Estudo qualitativo. & Acompanhante. & $\begin{array}{l}\text { Percepções positivas: relato de uma das } \\
\text { puérperas a presença do marido foi de } \\
\text { grande importância para não se sentir } \\
\text { sozinha e suportar o momento de dor. }\end{array}$ \\
\hline 7 & ALMEIDA JM, et al. (2015); & Estudo quantitativo, transversal. & $\begin{array}{l}\text { Banho de chuveiro; Bola Suíça; } \\
\text { Deambulação; Massagem. }\end{array}$ & $\begin{array}{l}\text { Percepções positivas: } 53 \% \text { das puérperas } \\
\text { relatou que o banho do chuveiro é um dos } \\
\text { preferido e citado como resolutivo. }\end{array}$ \\
\hline 8 & $\begin{array}{l}\text { ARAÚJO ROCHA FA, et al. } \\
\text { (2015); }\end{array}$ & $\begin{array}{l}\text { Pesquisa exploratória, com abordagem } \\
\text { qualitativa. }\end{array}$ & $\begin{array}{l}\text { Cavalinho; Bola Suíça; } \\
\text { Deambulação; Técnicas de } \\
\text { Respiração; Massagem; } \\
\text { Acompanhante. }\end{array}$ & $\begin{array}{l}\text { Percepcões positivas: relataram que o } \\
\text { cavalinho é bom porque aliviou um pouco a } \\
\text { dornas costas, outras relatou que a } \\
\text { massagem é muito boa porque relaxa e } \\
\text { alivia um pouco a dor, e acompanhante do } \\
\text { lado ajudou muito. } \\
\text { Percepcões negativas: Uma puérpera não } \\
\text { gostou dos métodos, pois queria ficar só } \\
\text { deitada mesmo. }\end{array}$ \\
\hline 9 & $\begin{array}{l}\text { BARBOSA DR e TORRES } \\
\text { GV (2017); }\end{array}$ & $\begin{array}{l}\text { Ensaio clínico quantitativo do tipo } \\
\text { intervenção terapêutica. }\end{array}$ & $\begin{array}{l}\text { Exercícios respiratório; } \\
\text { Relaxamento muscular; } \\
\text { Massagem lombassacral. }\end{array}$ & $\begin{array}{l}\text { Percepcões positivas: os exercícios } \\
\text { utilizados foram efetivos no alívio e conforto } \\
\text { da dor. }\end{array}$ \\
\hline 10 & $\begin{array}{l}\text { HANUM S dos P, et al. } \\
(2017) \text {; }\end{array}$ & $\begin{array}{l}\text { Pesquisa quase-experimental do tipo } \\
\text { intervenção terapêutica não controlada e não } \\
\text { randomizada, com abordagem quantitativa. }\end{array}$ & $\begin{array}{l}\text { Cavalinho; Bola Suíça; } \\
\text { Técnicas de Respiração; } \\
\text { Massagem; Acompanhante; } \\
\text { Banho Morno. }\end{array}$ & $\begin{array}{l}\text { Percepções positivas: relataram melhoras } \\
\text { da dor com os métodos empregadas, e } \\
\text { apontaram o banho morno como o melhor. }\end{array}$ \\
\hline 11 & LIMA PC, et al. (2017); & $\begin{array}{l}\text { Estudo descritivo-exploratório com } \\
\text { abordagem qualitativa. }\end{array}$ & $\begin{array}{l}\text { Acompanhante; Deambulação; } \\
\text { Posição ereta; Cavalinho; Bola } \\
\text { suíça; Banho de aspersão; } \\
\text { Massagens; Posição de quatro. }\end{array}$ & $\begin{array}{l}\text { Percepções positivas: relatou somente uma } \\
\text { das puérperas que afirmou que os } \\
\text { exercícios aliviaram a dor, e as demais não } \\
\text { comentou se houve ou não amenização da } \\
\text { dor. }\end{array}$ \\
\hline 12 & SOARES YKC, et al. (2017); & Estudo qualitativo, descritivo e exploratório. & $\begin{array}{l}\text { Acompanhante; Deambulação; } \\
\text { Exercício na banheira; Bola; } \\
\text { Agachamento; Massagem. }\end{array}$ & $\begin{array}{l}\text { Percepcões positivas: todos os exercícios } \\
\text { realizados aliviaram bastante a dor, } \\
\text { conforto, relaxamento, ficaram satisfeitas. }\end{array}$ \\
\hline
\end{tabular}

Fonte: Sousa AGN, et al., 2018. 
Por muitas vezes acreditamos que a tranquilidade e o contentamento emocional da parturiente durante 0 trabalho de parto passam pelo alívio da dor como uma das maneiras no cuidado e bem-estar no parto. Se considerarmos o cuidado e o bem-estar durante o trabalho de parto, sabemos que este não segue receitas e nem pode ser prescrito, mas pode ser vivido e sentido essa experiencia. Assim, podemos compreender que avaliar a opinião da mulher sobre sua perspectiva e sua vivencia a dor no seu parto é fundamental. Consta que a mulher no trabalho de parto sem dor terá uma experiência mais tranquila (ROCHA AM, et al., 2010).

No nosso estudo constatamos que a utilização dos MNFAD no trabalho de parto foi satisfatória pela maioria das puérperas proporcionando conforto e relaxamento e apenas três delas não obtiveram resultados favoráveis pelo medo de realizar os métodos e por não obter diferença na utilização deles.

\section{Acompanhante}

Existe uma Lei do Acompanhante - Lei 11.108 de 7 de abril de 2005, é um recurso que permite a presença do acompanhante durante o processo parturitivo e que o/a acompanhante seja a pessoa de escolha da mulher pois é essencial, o apoio contínuo propicia benefícios físicos e emocionais, tornando a parturiente mais segura e autônoma, contribuindo para uma boa evolução do trabalho de parto e parto, favorecendo a vivência positiva desse momento (FRIGO J, et al., 2013 e SANTOS ALS, et al., 2015).

Em relação ao acompanhante, dezessete puérperas foram acompanhadas por seu cônjuge, duas delas foram sozinhas e conduzidas pela ambulância e pelos bombeiros, outra foi enviada para o hospital pela sua mãe e outras duas mulheres gravidas por outros parentes. Ao falar da presença do acompanhante para 21 mulheres foi ofertada a liberdade de escolha, das parturientes em estudo, apenas quatro ficaram sozinhas e dentro desse estudo foi observado no relato de uma das gestantes que a presença do cônjuge foi de grande importância para não se sentir sozinha e suportar esse momento de dor (FRIGO J, et al., 2013).

A assistência do acompanhante revela que é essencial e pode ser observada também nas falas de duas puérperas, que uma teve acompanhamento direto e na outra pode perceber o apreço de ter ao lado sua irmã ao seu lado lhe dando suporte e força em um simples aperto de mão ( LIMA PC, et al., 2017). É possível notar no depoimento de outra puérpera que a companhia dos acompanhantes ajuda de forma positiva no processo de trabalho de parto, os relatos revelaram um maior conforto e tranquilidade frente a presença do acompanhante, também foi apontada pelas participantes como uma das técnicas utilizadas no trabalho de parto mais relaxante e prazerosa. É uma terapêutica simples e de baixo custo, que pode ser de grande valia no processo do nascimento. (ROCHA FAA, et al., 2015).

Os resultados destacam a participação do acompanhante como marcador importante para a satisfação das puérperas no processo de parturição. Dentre os benefícios elencados, observou-se que as mulheres se sentiram mais seguras, amparadas e encorajadas para parir. Esses benefícios contribuem tanto para uma melhor experiência no processo do parir como para um bom desfecho do parto. (SOARES YK, et al., 2017).

\section{Bola suíça}

A utilização da bola suíça foi evidenciada em seis artigos. E a mesma é usada para facilitar a postura vertical pela parturiente de forma aconchegante, trabalha os músculos da região pélvica, além de ser uma opção de escolha dos exercícios, tendo como efeito a participação ativa das gestantes no processo de parto, ajuda a descida e rotação da apresentação do bebê e estimula a dilatação uterina. No depoimento de uma puérpera, diz que o uso da bola proporcionou aliviou a dor, obteve conforto e teve uma percepção da redução do tempo de trabalho de parto (LIMA PC, et al., 2017 e SOARES YK, et al., 2017).

\section{Cavalinho}

Uma paciente revelou que não tinha conhecimento quanto à existência do método da bola e do cavalinho, sendo este um objeto que a maternidade campo da pesquisa deste estudo usa como técnica para ajudar no alívio da dor e como um progresso do trabalho de parto, já no comentário de um outro estudo mostra o conhecimento sobre o método pelas puérperas e o uso do mesmo, pois proporcionou o alivio da dor, principalmente na região dorsal, este método consiste em um assento com apoio para colocar os braços, o que favorece uma postura sentada com as a região dorsal para frente e promove uma dilatação na região pélvica (SESCATO AC, et al., 2008 e ROCHA FAA, et al., 2015). 


\section{Deambulação}

Com base nos relatos dos periódicos encontrados, a independência para deambular foi mostrada pelas puérperas como de grande importância para aguentar e aliviar as dores do processo de parto, pois assim desvia a concentração da mulher na dor (YI WEI C, et al., 2011). O efeito de caminhar diminui o uso de medicamentos para aliviar a dor, além da menor frequência de parto normal com a utilização de fórceps, episiotomia, extração a vácuo entre outros (MAMEDE FV, et al., 2007).

Ainda que as parturientes considerem a posição deitada desfavorável e decidem se mexer outras desejam permanecer deitadas durante os momentos de dores do trabalho de parto, relacionando a isso às divergências de cada organismo, que se comunica de modo diferente para cada mulher, sabendo disso, mesmo recebendo orientação de um profissional, a gestante muitas vezes se recusa a caminhar (YI WEI C, et al., 2011).

\section{Exercícios de respiração}

Nos artigos verificou-se o uso do exercício respiratório, sempre associado com outras técnicas. Ao utilizar os métodos não farmacológicas de alivio da dor (MNFAD) associados com exercícios respiratórios, relaxamento dos músculos e massagem na região lombar é perceptível o alívio da dor das parturientes havendo redução da sua força nos oito centímetros depois da aplicação dos métodos juntos, comparada aos seis centímetros antes na utilização das mesmas, bem como nos nove centímetros após a aplicação dos MNFAD, quando comparada aos oito centímetros antes desses métodos, pois, seria esperado em condições fisiológicas que a dor fosse de grande intensidade à medida que a abertura do colo uterino evoluía entre seis e nove centímetros no momento do trabalho de parto (DAVIM RMB, et al., 2007).

\section{Massagem e relaxamento muscular}

A massagem tem o potencial de possibilitar o alívio da dor, estabelece contato direto com a parturiente, potencializa o efeito de relaxamento, melhora a oxigenação dos tecidos, e reduz o estresse emocional. A massagem é geralmente aplicada na região lombar durante as contrações uterinas ou onde a parturiente preferir (LIMA PC, et al., 2017).

Este método foi o terceiro mais utilizado entre os outros usados nas pacientes, no entanto vale ressaltar que esta é uma técnica que não depende da gestante para ser realizada, mas sim de uma segunda pessoa, no caso realizado mais por um acompanhante, é um método bem aceito pelas pacientes que receberam sua utilização como cuidado não farmacológico (SESCATO AC, et al., 2008). Também foi relatado pelas puérperas que realizaram a massagem, como uma das técnicas utilizadas no trabalho de parto mais relaxantes e prazerosas. Sendo esta uma conduta simples e de baixo custo, que pode ser de grande valia no processo do parto (ROCHA FAA, et al., 2015).

\section{Banho de chuveiro ou aspersão}

Em algumas maternidades o banho de imersão ainda não se é utilizado, pois a área física de algumas não sustenta a instalação de banheiras, no entanto, o banho de chuveiro com agua morna é um dos métodos feito para amenizar a dor no trabalho de parto, pois a água aquecida impulsiona a estimulação cutânea de calor que é realizado a uma temperatura de mais ou menos $37^{\circ} \mathrm{C}$, está relacionado com a diminuição da dor, ansiedade, medo e estresse durante o trabalho de parto, acontece uma melhora no padrão das contrações uterina e ajuda na dilação (LIMA PC, et al., 2017).

O banho de chuveiro diminuiu o tempo do trabalho de parto e a água atuou no local da dor, reduzindo a sensação da dor, tendo o relaxamento nas gestantes. Em outro ensaio clínico, certificou que o banho de aspersão na fase ativa do tempo de dilatação proporcionou sensações de alívio, conforto, bem-estar e revigoramento, provocando satisfação nas parturientes em experimento (ROCHA FAA, et al., 2015).

\section{Movimentação (posição vertical, agachamento, balanço pélvico e posição de quatro)}

Foi percebido pelo relato de algumas puérperas que os exercícios ajudam a o trabalho de parto ser mais rápido, favorece a posição vertical, facilita o processo de dilatação, diminuindo a dor e ajuda na ação da gravidade. E mesmo com esses benefícios algumas delas não querem realizar nenhum exercício ou não se 
sentem à vontade para fazê-los, seja por conta da dor ou por outros motivos, pois é necessário que o desejo da gestante seja respeitado (LIMA PC, et al., 2017).

A movimentação favorece o alívio da dor, mas algumas puérperas tiveram uma visão negativa, estabelece a vontade por permanecer deitada, por medo de seu bebê nascer durante a movimentação e acabar caindo no chão e à complexidade de fazer força na posição vertical, a posição deitada foi vista por algumas parturientes como mais fácil para se fazer força (YI WEI C, et al., 2011).

Ao fazer os alguns movimentos a puérpera passa a exercer um certo controle do seu corpo, tornando-se como a principal do processo, Além disto, os exercícios facilita na posição vertical, melhorando o trabalho de dilatação o que acelera o parto, aumenta a força e eficácia das contrações, reduzindo a dor ( LIMA PC, et al., 2017).

$\mathrm{Na}$ aplicação dos métodos de relaxamento muscular em gestantes, durante o trabalho de parto, verificou-se que esse método causa a percepção no alívio da dor manifestada pelas puérperas. Isso é essencial à medida que é obtido resultados durante aplicação desses métodos, observou uma importante redução no nível de dor das puérperas (ROCHA FAA, et al., 2015).

\section{CONSIDERAÇÕES FINAIS}

Este estudo permitiu evidenciar que poucos trabalhos de campo foram realizados com esse tema. Para algumas puérperas nem todos os MNFAD são perceptivos como eficazes, mas no relato da maioria das puérperas pode sim causar menos dor, diminuindo os níveis de ansiedade e estresse. Os métodos mais utilizados foram o da massagem, acompanhante, banho de chuveiro ou aspersão com maior efetividade na fase ativa do trabalho de parto, sendo associados com outros métodos como: exercício respiratório e deambulação. Desta forma, evidencia-se a relevância de uma atenção integral e individualizada, considerando os aspectos emocionais, sociais, culturais e psicológicos da parturiente e de sua família.

\section{REFERÊNCIAS}

1. ALMEIDA JM, et al. Conhecimento das puérperas com relação aos métodos não farmacológicos de alívio da dor do parto. Revista Mineira de Enfermagem, 2015; 19(3): 711-724.

2. ARAÚJO ROCHA FA, et al. Cuidado no parto e nascimento: percepção de puérperas. Revista da Rede de Enfermagem do Nordeste, 2015; 16(6).

3. BARBOSA DR, TORRES GV. Avaliação do uso de estratégias não farmacológicas no alívio da dor de parturientes. Revista da Rede de Enfermagem do Nordeste, 2008; 9(2).

4. BRASIL. Conselho Nacional de Saúde. 2015. Resolução 466/12. Trata de pesquisas em seres humanos e atualiza a resolução 196. 2012. 2018.

5. BRASIL. Ministério da Saúde. 2002. Programa de Humanização do Parto: humanização pré-natal e nascimento. Ministério da Saúde, Secretaria de Atenção à Saúde, Departamento de Ações Programáticas Estratégicas. Brasília (DF): Ministério da Saúde.

6. CAMARGO BV, JUSTO AM. IRAMUTEQ: um software gratuito para análise de dados textuais. Temas em psicologia, 2013; 21(2): 513-518.

7. DAVIM RMB, et al. Estratégias não farmacológicas no alívio da dor durante o trabalho de parto: pré-teste de um instrumento. Revista Latino-Americana de Enfermagem, 2007; 15(6): 1150-1156.

8. DAVIM RMB, et al. Banho de chuveiro como estratégia não farmacológica no alívio da dor de parturientes. Revista eletrônica de Enfermagem,2008; 10(3).

9. FORMIGA AC, et al. Implementação de práticas humanizadas no alívio da dor durante o trabalho de parto. Enfermagem Obstétrica, 2016; 3: 52.

10. FRANKLIN JS, BITTAR CMA. Humanização do parto. Relatos de puérperas e profissionais de um centro obstétrico de um hospital privado em um município de franca. INVESTIGAÇÂO, 2015; 14(2).

11. FRIGO J, et al. Assistência de enfermagem e a perspectiva da mulher no trabalho de parto e parto. Cogitare Enfermagem, 2013; 18(4).

12. HANUM SP, et al. Estratégias não farmacológicas para o alívio da dor no trabalho de parto: efetividade sob a ótica da parturiente. Rev. enferm. UFPE on line, 2017; 11(8): 3303-3309.

13. KATZER T. Métodos não farmacológicos para o alívio da dor: percepções da equipe multiprofissional no trabalho e parto. Trabalho de Conclusão de Curso (Graduação em Enfermagem). Universidade de Santa Cruz do Sul, 2016; $44 p$.

14. LIMA PC, et al. A vivência de adolescentes assistidas por enfermeiros obstetras durante o processo de parturição. Revista de Enfermagem do Centro-Oeste Mineiro,2017; 7. 
15. MAMEDE FV, et al. Reflexões sobre deambulação e posição materna no trabalho de parto e parto. Esc Anna Nery, 2007; 11(2): 331-6.

16. MENDES KDS, et al. Revisão integrativa: método de pesquisa para a incorporação de evidências na saúde e na enfermagem. Texto Contexto Enferm,2008; 17(4): 758-64.

17. MIQUELUTTI MA, et al. The vertical position during labor: pain and satisfaction. Revista Brasileira de Saúde Materno Infantil, 2009; 9(4): 393-398.

18. MEDEIROS J, et al. Métodos não farmacológicos no alívio da dor no parto: percepção de puérperas. Espaço para a Saúde-Revista de Saúde Pública do Paraná, 2015; 16(2): 37-44.

19. PEREIRA TCB, et al. Métodos não farmacológicos para alívio da dor no trabalho de parto: uma revisão sistêmica de literatura. Trabalho de Conclusão de Curso (Graduação em Enfermagem). Repositório Institucional Escola Bahiana de Medicina e Saúde Pública, 2016.

20. ROCHA A, et al. Cuidados no alívio da dor: perspectiva da parturiente. Millenium, 2010; 299-309.

21. Rocha FAA, et al. Cuidado no parto e nascimento: percepção de puérperas. Revista da Rede de Enfermagem do Nordeste, 2015; 16(6): 782-789.

22. SANTOS AC, MONTEIRO RL. Métodos não farmacológicos utilizados pelo enfermeiro para alívio da dor no trabalho de parto. Nanbiquara,2017; 6(1).

23. SANTOS ALS, et al. O acompanhante no trabalho de parto sob a perspectiva da puérpera. Rev Enferm UFSM, 2015; 5(3): 531-40.

24. SESCATO AC, et al. Os cuidados não-farmacológicos para alívio da dor no trabalho de parto: orientações da equipe de enfermagem. Cogitare Enfermagem, 2008; 13(4).

25. SOARES YKC, et al. Satisfação das puérperas atendidas em um centro de parto normal. Rev. enferm. UFPE on line, $2017 ; 11(11)$ : 4563-4573.

26. TRINDADE FC. Assistência humanizada para o alívio da dor do parto: revisão bibliográfica. Artigo (Bacharelado em Enfermagem). Centro Universitário São Lucas,2017; 15p.

27. YI WEI C, et al. Movimentação e dieta durante o trabalho de parto: a percepção de um grupo de puérperas. Texto \& Contexto Enfermagem, 2011; 20(4). 